\title{
REDE REGIONAL NORTE E NORDESTE DE ESTUDOS E PESQUISAS SOBRE A MULHER E RELAÇÕES DE GÊNERO
}

\author{
Ana Alice Alcântara Costa* \\ Cecília Maria Bacellar Sardenberg**
}

A crescente mobilização de mulheres em torno de questões específicas à condição feminina em nossa sociedade, vem gerando, na última década, um excepcional interesse em estudos e pesquisas concernentes à mulher, dando margem ao surgimento de gnupos e núcleos de estudos nessa área, em associações científicas nacionais, bem como em diferentes universidades brasileiras.

Congregando professores e pesquisadores que, de um modo geral, já desenvolviam trabalhos nessa linha de pesquisa, não raro de forma isolada, esses grupos e núcleos de estudos vêm se constituindo em espaços privilegiados para a necessária permuta de informações e o aprofundamento de questões teóricometodológicas, contribuindo, assim, para o avanço da discussão em torno da problemática da mulher e para o desenvolvimento desse novo e auspicioso campo de reflexão sobre a sociedade brasileira.

No entanto, em que pese sua relevância, sérios entraves vêm emperrando o processo de criação, afirmação e sobrevivência desses núcleos, dificultando muitas vezes seu funcionamento e sua atuação continuada.

De fato, como ficou patente nas discussões travadas durante o I Encontro Nacional de Núcleos de Estudos sobre a Mulher nas Universidades Brasileiras (promovido pelo NEMGE/USP, em São Paulo em março de 1991) - quando se reuniram representantes dos diferentes núcleos no país- a trajetória da maior parte desses Centros tem sido marcada por um processo de lutas, que vêm se travando em dois planos ou "frentes de batalhas". De um lado, é necessário reafirmar, constantemente, a legitimidade científica da "questão da Mulher" e seus desdobramentos enquanto objeto de análise e, assim, deixar clara a necessidade de incentivos aos estudos e pesquisas nessa área, principalmente através da criação de no- vos núcleos específicos nas instituições universitárias. De outro lado, trava-se um embate contra a burocracia estatal e as políticas atuais de contenção de verbas para as universidades e fomento à pesquisa básica, que têm não só concorrido para o processo de sucateamento das instituições públicas de ensino superior (sobretudo as federais), dificultando inclusive a realização de sua atividade fim, como vêm criando inúmeros obstáculos no sentido da garantia de um apoio institucional mais eficaz à captação dos recursos necessários à manutenção desses núcleos e a viabilização de suas propostas de trabalho.

Vale lembrar que esses problemas de natureza "econômico-administrativa", não penalizam tão somente os núcleos de estudos sobre a mulher. Ao contrário, eles atingem a comunidade científico-acadêmica como um todo. Entretanto, na medida em que a relevância científica dos estudos nessa área ainda não foi de todo reconhecida, ao menos em termos de prioridades quanto ao apoio efetivo das agências financiadoras, os recursos disponíveis para as pesquisas na temática da mulher ainda permanecem bastante escassos. Essa situação vem criando um ambiente de competição contraprodutivo entre os diferentes núcleos e pesquisadores, desfavorecendo sobretudo aqueles das regiões Norte e Nordeste, que não se beneficiam dos recursos acadêmicos provenientes de outras áreas do país, por acaso mais desenvolvidas.

Sabe-se que o processo de desenvolvimento "desigual e combinado", característico do avanço do sistema capitalista também na formação social brasileira, tem engendrado, historicamente, a configuração de disparidades marcantes entre os diferentes estados e regiões do país, sendo que , de um modo geral, os estados das regiões Norte e Nordeste, incluem-se, ainda hoje, entre aqueles ditos "menos desenvolvidos".

* Prof essora do Departamento de Ciência Politica da Faculdade de Filosofia e Ciências Humanas da Universidade Federal da Bahia, Coordenadora do Núcleo de Estudos Interdisciplinares sobre a Mulher-NEIM.

** Prof essora do Departamento de Antropologia da Faculdade de Filosofia e Ciências Humanas da Universidade Federal da Bahia, Vice-Coordenadora do Núcleo de Estudos Interdisciplinares sobre a Mulher - NEIM. 
Sem dúvida os avanços do capitalismo no Brasil nas últimas décadas, têm provocado surtos de dinamismo econômico e de "modernização", inclusive em áreas remotas dessas regiões. Contudo, as disparidades regionais não foram de todo superadas. Elas ainda permanecem bastante acentuadas, e não apenas no que se refere aos aspectos sócio-econômicos, mas também no plano cultural e do desenvolvimento científico. Na verdade, verifica-se, atualmente, uma nítida concentração aos estados do Centro-Sul, de centros de formação e capacitação de pesquisadores (os cursos de doutorado, por exemplo), pessoal qualificado, seminários e encontros de associações científicas, organismos de divulgação e, principalmente, dos recursos de fomento à pesquisa, existentes no país. Não se dá portanto ao azar, o fato de que são as universidades e demais centros de pesquisas, alí localizado, que respondem pelos mais elevados índices da produção científica nacional.

Se, como diz o velho ditado, "dinheiro gera dinheiro", também a concentração desses recursos científico-acadêmicos no Centro-Sul, tende a gerar mais recursos dessa ordem para a região, ao passo que, salvo raras exceções, os centros de pesquisas situados em outras áreas do país, sobretudo nas regiões Norte-Nordeste, vêem-se emaranhados nas teias do círculo vicioso da "baixa produção científica", concorrendo, assim, em franca desvantagem pelos recursos progressivamente mais escassos para o fomento à pesquisa.

Um dos principais fatores responsáveis pela reprodução desse círculo vicioso, prende-se, certamente, ao fato de que, os centros de pesquisa das regiões Norte-Nordeste, em sua grande maioria, estão vinculados à Instituições Federais de Ensino Superior (IFES). Destarte, vêem-se invariavelmente sujeitos à crônica escassez de verbas e de incentivos, funcionando sem as mínimas condições de trabal ho: salários indignos, instalações precárias, bibliotecas defasadas, etc. Além disso, as grandes distâncias geográficas existentes não só entre o Norte-Nordeste e o Centro-Sul, como também entre os próprios centros norte-nordestinos, dificultam sobremaneira o necessário intercâmbio de informações e conhecimento entre eles. Na verdade, ao contrário do que se poderia esperar, o intercâmbio inter-regional com o CentroSul, tem sido muitas vezes mais intenso do que o estabelecido entre os centros da própria região Norte-Nordeste, levando inclusive à configuração de descompassos, também a nível intra-regional. Sem falar no que se perde em termos da possibilidade de realização de pesquisas conjuntas, voltadas para a análise de problemas regionais.

Cumpre ressaltar que apesar dessas dificuldades, vários núcleos de estudos sobre a mulher foram criados em universidades da região Norte-Nordeste, sendo que, atualmente, encontram-se em funcionamento um total de 10 (dez) núcleos, a saber:

1. Núcleo de Estudos Interdisciplinares Sobre a Mulher - NEIM

Faculdade de Filosofia e Ciências Humanas Universidade Federal da Bahia

2. Núcleo Temático Mulher e Cidadania - NTMC Universidade Federal de Alagoas

3. Coordenadoria de Estudos da Mulher Fundação Joaquim Nabuco (Pernambuco)

4. Núcleo de Estudos e Pesquisas sobre a Mulher Departamento de Ciências Domésticas Universidade Federal Rural de Pernambuco

5. Grupo "Fazendo o Gênero" Centro Josué de Castro (Pemambuco)

6. Núcleo de Documentação Histórico Regional Universidade Federal da Paraíba

7. Núcleo Nízia Floresta de Estudos e Pesquisas sobre a Mulher e Relações Sociais de Gênero Universidade Federal do Rio Grande do Norte

8. Núcleo de Estudos, Documentação e Informação sobre a Mulher

Universidade Federal do Ceará

9. Núcleo de Estudos Mulher e Saúde - MUSA

Departamento de Medicina Preventiva

Universidade Federal da Bahia

\section{Grupo de Estudos sobre Saúde da Mulher \\ Escola de Enfermagem \\ Universidade Federal da Bahia}

Esses núcleos, mesmo lutando "contra a maré", vêm desenvolvendo diversas atividades nas áreas de ensino, pesquisa e extensão, tendo produzido estudos relevantes sobre relações de gênero e condição feminina no Norte-Nordeste. É portanto, lastimável saber, que muitos desses estudos não têm encontrado vias de divulgação, permanecendo conhecidos apenas nos limites dos núcleos em que se realizam ou, no máximo, nas universidades em que se localizam. Se isso já é frustrante para aqueles que, de alguma forma, encontram respaldo no interior dos núcleos, o que não dizer dos pesquisadores isolados, que nem ao menos podem se valer de um espaço onde suas inquietações e interesses tenham maior ressonância? 
Cientes desses problemas, entidades como a Associação Nacional de Pós-Graduação e Pesquisa cm Ciências Sociais - ANPOCS e a Associação Brasileira de Antropologia - ABA, vêm apoiando a formação de grupos de estudos, bem como, a realização de encontros regionais no Norte-Nordeste, contribuindo, assim, para uma aproximação e o necessário intercâmbio entre os pesquisadores da região. Nessas instâncias, a exemplo do que se verificou no II Encontro de Antropologia do Norte-Nordeste (Recife, fevereiro de 1991) e do que tem acontecido nos encontros anuais da Articulação de Centros de Pesquisas e PósGraduação do Nordeste (particularmente no Grupo de Pesquisa. "Relações de Trabalho, Relações de Poder"). Um cspaço vem sendo criado para o avanço da discussão $\mathrm{cm}$ tomo da problemática da mulher, através de sessões e grupos de trabalho específicos.

Essas iniciativas merecem destaque não somente por divulgarem a produção científica nessa temática nos cstados do Norte-Nordeste, mas também por se constituírem numa importante fonte de incent ivo para novos estudos e pesquisas nessa área. Note-se porém, que $\mathrm{cm}$ que pese sua inegável relevância, tais iniciativas não têm sido suficiente como canais para uma aproximação $c$ intercâmbio mais sistemático entre os vários pesquisadores e núcleos da região. Na verdade, estamos convencidas de que esse necessário entrosamento, só poderá ser articulado com verdadeira eficácia, através da promoção de eventos específicos à temática, juntamente à criação de um organismo próprio, de caráter regional, que atenda aos interesses e necessidades dos pesquisadores e núcleos de estudos sobre a mulher, do Norte-Nordeste.

É nessa perspectiva de construir este espaço específico de articulação e intercâmbio, que mais de 40 pesquisadoras representantes dos diversos Núcleos de Estudos da Região, reunidas no I Encontro Regional de Estudos sobre a Mulher e Relações de Gênero do Norte/Nordeste ${ }^{*}$ deliberaram pela criação da Rede Regional Norte e Nordeste de Estudos e Pesquisas sobre a Mulher e Relações de Gênero. Essa decisão lastreou-se não apenas nas discussões relativas aos problemas aqui referidos, mas também na avaliação crítica dos avanços e conquistas no campo dos estudos sobre a mulher e relações de gênero no país. Constatou-se, então, que mesmo tendo-se avançado consideravelmente no desenvolvimento desses estu- dos, observa-se ainda hoje, no interior da comunidade científica, uma tendência à marginalização e segregação desse campo. A começar pelo fato de que os grupos de trabalho e núcleos de estudos sobre a mulher, ainda se constituem como verdadeiros "guetos femininos" dentro das entidades científicas e universidades, seja em termos do sexo da maioria dos seus membros (são majoritária, senão exclusivamente compostos por mulheres), seja no alcance, circuito e retroalimentação ("feedback") da produção ali desenvolvida. Poder-se-ia até mesmo afirmar que esses centros, são grupos de mulheres, escrevendo sobre mulheres, para um público composto essencialmente de mulheres.

Sc, nesse ponto, se assemelham aos "grupos de reflcxão" ou de "conscientização" que marcaram, $\mathrm{cm}$ todo mundo, o ressurgimento do movimento feminista, sendo um espaço específico para reflexões $\mathrm{cm}$ torno da questão da mulher, por outro, os núcleos de cstudos da mulher são a expressão de um momento. ou de uma fase imprescindível na constituição de um novo campo do saber, fase esta na qual vem se processando a construção do seu objetivo de estudo.

Nesse sentido, é importante salientar que vive-se agora um momento crucial na trajetória de constituição desse campo do saber, momento esse que se descortina com a proposição do "gênero", dentro de uma perspectiva relacional, enquanto categoria fundamental de análise. Para além de um avanço epistemológico nesse campo do saber - construiu-se, por fim, um "objeto formal" -, a proposição do "gênero" representa também a possibilidade, um caminho, ou mesmo um novo desafio no sentido da derrubada das paredes do "gueto" e a conquista de um espaço para reflexões em outro nível, bem mais amplo, que atravesse outros campos do saber e temáticas.

Tentativas na conquista desse espaço têm sido feitas, inclusive por iniciativa dos GT's da ANPOCS, a exemplo da mesa redonda da "Transversalidade do Gênero", realizada em 1990, durante o XV Encontro Nacional. Sabe-se, porém, que o reconhecimento da relevância da categoria "Gênero" como instrumento fundamental de análise para todos que objetivam um conhecimento prof undo das sociedades humanas, em seus múltiplos níveis e aspectos, não virá automaticamente, mas sim a partir de uma luta a ser travada, tanto no plano teórico-metodológico, quanto na arena

Este I Encontro foi realizado em Salvador, promovido pelo Núcleo de Estudos Interdisciplinares sobre a Mulher - NEIM/UFBa., com o apoio da Fundação Ford e do CNPq, no periodo de 08 a 12 de setembro de 1992. 
das instituições e instâncias científico-acadêmicas, nas quais se incluem, naturalmente, as universidades.

Nesse processo, portanto, os Núcleos de Estudos sobre a Mulher terão certamente um papel fundamental a cumprir, o que torna imprescindível a definição de políticas para uma ação conjunta. Elas deverão ser orientadas não apenas no sentido do aprofundamento das reflexões teórico-metodológicas em torno do conceito de gênero, mas também para uma ampla disseminação e divulgação da produção resultante, entre interlocutores de outros campos e áreas do saber. De um lado, isso implicará, necessariamente, na criação de Redes Regionais e de uma Rede Nacional de Núcleos da Mulher, com o propósito de estabelecer relações mais estreitas entre eles, possibilitando o desenvolvimento de estudos e pesquisas conjuntas, e o necessário intercâmbio de informações, experiências e sugestões, tendo em vista os objetivos comuns nessa luta. De outro, faz-se necessário uma postura de abertura dos núcleos, no sentido da busca de uma aproximação cada vez maior com outros espaços específicos e outros campos do saber, através da realização de seminários e do desenvolvimento de pesquisas conjuntas, principalmente em torno de temas interdisciplinares, já abertos a um reconhecimento da relevância e da "transversalidade" da catcgoria "gênero".

Tudo isso torna imprescindível a busca de uma aproximação maior entre pesquisadores e núcleos de estudos sobre a mulher do Norte/Nordeste, para que conjuguem esforços no sentido de se minimizar as discrepâncias regionais hoje existentes em relação ao Centro-Sul, em todos os níveis, inclusive no que se refere aos avanços nos estudos e pesquisas em tomo da problemática do gênero e condição feminina em nossa sociedade. É preciso que os núcleos da região Norte-Nordeste, aprofundem também as discussões em torno dessas questões, priorizando, sempre, as análises voltadas para os problemas de cunho regional. Um espaços nesse sentido seria a Rede.

\section{OBJETIVOS DA REDE}

- incentivar a formação de novos Núcleos de Estudos e Programas de Estudos sobre a Mulher, não só nas IFES como também nas demais Instituições de Pesquisas e Ensino Superior (Estaduais e Particulares).

- incentivar a produção teórico-metodológica na questão de gênero na região;

- fomentar o desenvolvimento de estudos e pesqui- sas intra e inter-regionais;

- implementar o intercâmbio de informações e conhecimentos;

- divulgar a produção científico-acadêmica regional;

- cstimular a capacitação de pessoal docente e técnicos envolvidos/associados aos núcleos e grupos de cstudos;

- promover a realização de seminários de pesquisas em torno dessa temática, visando a sua divulgação, intercâmbio de informações e aprofundamento das questõcs teórico-metodológicas entre os Núcleos da Universidades do Norte/Nordeste;

A Rede define sua atuação em três grandes linhas de trabalho:

- Estudos e Pesquisas;

- Capacitação;

- Publicação.

Estas linhas explicitam-se em:

- realização de seminários e encontros de trabalhos inter-regionais;

- promoção de cursos de capacitação e formação de profissionais especializados;

- publicação de um boletim informativo a ser distribuído entre os diversos núcleos e grupos participantes da Rede;

- publicação de anais dos encontros de trabalho e seminários;

- intercâmbio de pesquisadores através de programas de professor visitante, pesquisas conjuntas, estágios e cursos;

- montagem de um sistema de documentação e informação.

\section{ESTRUTURA DA REDE}

A Rede se constitui de Núcleos ou Grupos cujo objetivo seja o estudo e pesquisas sobre a mulher, nas várias instituições de pesquisas e ensino superior do Norte/Nordeste, e de pesquisadores de comprovada atuação na área, comprometidos em articular a criação de núcleos na instituição a qual pertencem.

A instância de deliberação da Rede é a Assembléia Geral, onde apenas votam as representantes de núcleos e as membras fundadoras.

Sua estrutura básica é definida por coletivos, operacionais e temáticos, em um total de 11 (onze), 
reunidos em 02 (dois) grandes grupos a saber:

\section{Coordenação político-administrativa}

Composta de 05 (cinco) membros e uma secretária, com a missão executiva de gerenciar e articular as linhas de trabalho da Rede, funcionando à base de uma Comissão-Sede representada por 02 (dois) membros, e das Comissões de Capacitação, de Publicação e de Estudos e Pesquisas com uma representante cada.

\section{Corpo político-temático}

Composto de 07 (sete) representantes, com a missãodearticularos membros da Rede para geração, repasse e difusão de conteúdos nos marcos dos temas: Violência; Participação Política e Feminismo: Teoria e História; Gênero e Identidade; $\mathrm{Mu}$ lher e Literatura; Mulher e Educação; Revisitando o Corpo; Mulher, Meio Ambiente e Desenvolvimento. 